Personalidade Acadêmica Homenageada:

Florisbal de Souza Del'Olmo (Professor Convidado - UNICURITIBA)

\title{
DESENVOLVIMENTO SUSTENTÁVEL E A EXTRAFISCALIDADE DO ISS E IPTU APLICADO À CONSTRUÇÃO CIVIL
}

\section{VALMIR CÉSAR POZZETTI}

Doutor em Biodireito/Direito Ambiental pela Université de Limoges/França. Mestre em Direito do Urbanismo e Meio ambiente pela Université de Limoges/França. Professor Adjunto da UFAM - Univ. Federal do Amazonas e da UEA - Universidade do Estado do Amazonas.

\section{VINICIUS RIBEIRO DE SOUZA}

Mestrando do PPGDA - Programa de Pós-Graduação em direito ambiental da UEA - Universidade do Estado do Amazonas.

\section{MARCELO ANTUNES SANTOS}

Mestrando do PPGDA - Programa de Pós-Graduação em direito ambiental da UEA - Universidade do Estado do Amazonas.

\section{OBJETIVOS DO TRABALHO}

O objetivo desta pesquisa é o de verificar a possibilidade de implementação de Lei municipal que discipline a extrafiscalidade do ISS (Imposto sobre serviço de qualquer natureza) e do IPTU (Imposto Territorial Urbano) em relação às atividades da construção civil.

Assim considerando, a problemática desta pesquisa é: de que forma o Estado poderá incentivar as grandes construtoras a praticarem suas atividades de modo sustentável, buscando condutas que minimizem os impactos ambientais ínsitos ao ofício? 
Personalidade Acadêmica Homenageada:

Florisbal de Souza Del'Olmo (Professor Convidado - UNICURITIBA)

\section{METODOLOGIA UTILIZADA}

A metodologia utilizada, no que concerne aos meios e fins, será bibliográfica, onde se fará uso da doutrina e das legislações comparadas. De igual modo será qualitativa à medida que busca a análise de comportamentos, levando em consideração a questão subjetiva da problemática.

\section{REVISÃO DE LITERATURA}

A expansão das atividades da construção civil requer uma percepção cuidadosa a respeito da temática ambiental. $\mathrm{O}$ uso de matéria-prima sem critérios que visem a proteção do meio ambiente pode ocasionar grave dano a longo prazo. Assim, é imprescindível a união do interesse empresarial com a salvaguarda do meio ambiente.

E essa ideia de conciliar a lucratividade e sustentabilidade pode ser alcançada por meio dos impostos, mais precisamente nas características da extrafiscalidade do ISS (Imposto sobre serviço de qualquer natureza) e do IPTU (Imposto Territorial Urbano).

Nessa medida, insta destacar que o imposto pode ser classificado em fiscal e extrafiscal. Aquele, conforme Alexandre ${ }^{1}$, ocorre "quando visa precipuamente a arrecadar, carrear recursos para os cofres públicos. São os casos do ISS, do ICMS, do IR e de diversos outros" (2017, p. 115). Quanto a este, explica o autor:

O tributo possui finalidade extrafiscal quando objetiva fundamentalmente intervir numa situação social ou econômica. São os casos, entre outros, dos impostos de importação e exportação, que, antes de arrecadar, objetivam o controle do comércio internacional brasileiro, podendo, às vezes, servir de barreira protetiva da economia nacional e outras de estímulo à importação ou exportação de determinada espécie de bem. ${ }^{2}$ ( grifo nosso).

\footnotetext{
${ }^{1}$ ALEXANDRE, Ricardo. Direito Tributário.11를. Salvador: JusPodivm, 2017, p. 115.

2 ALEXANDRE, Ricardo. Direito Tributário.11 ${ }^{\mathrm{a}} \mathrm{ed}$. Salvador: JusPodivm, 2017, p. 115.
} 
Personalidade Acadêmica Homenageada:

Florisbal de Souza Del'Olmo (Professor Convidado - UNICURITIBA)

A Respeito da extrafiscalidade e sua importância na moldura dos comportamentos positivos e no combate ás ações poluidoras em referência ao meio ambiente, Pozzetti e Campos ${ }^{3}$ assim afirmam:

\begin{abstract}
A implementação do Princípio Poluidor Pagador conduz, necessariamente, à tributação ambiental, como instrumento de prevenção, recuperação e combate à poluição, nas formas de tributação fiscal (adequação das espécies tributárias para arrecadação de recursos destinados ao custeio da proteção ambiental) e extrafiscal (para incentivar comportamentos preservadores do meio ambiente e combater comportamentos poluidores). (g.n )
\end{abstract}

No que tange ao ISS, a Constituição Federal, em seu artigo 156, III, prevê a competência municipal para sua instituição. Igualmente, dispõe a Carta Magna que caberá à Lei Complementar fixar as suas alíquotas máximas e mínimas, bem como regular a forma e as condições como isenções, incentivos e benefícios fiscais que serão concedidos e revogados, senão vejamos:

\begin{abstract}
Art. 156. Compete aos Municípios instituir impostos sobre: [...]omissis III serviços de qualquer natureza, não compreendidos no art. 155, II, definidos em lei complementar. [...]omissis § $3^{\circ}$ Em relação ao imposto previsto no inciso III do caput deste artigo, cabe à lei complementar: I fixar as suas alíquotas máximas e mínimas; II - excluir da sua incidência exportações de serviços para o exterior. III - regular a forma e as condições como isenções, incentivos e benefícios fiscais serão concedidos e revogados. (g.n).
\end{abstract}

Por conseguinte, a LC ำ 116/2003, a qual disciplina a matéria, foi alterada pela Lei Complementar ํㅜ 157/2016, sendo que, de acordo com Alexandre ${ }^{4}$, o "Congresso Nacional finalmente regulamentou o dispositivo constitucional, estabelecendo regras bastante semelhantes àquelas constantes do citado dispositivo do ADCT".

\footnotetext{
${ }^{3}$ POZZETTI, Valmir César; CAMPOS, Jalil Fraxe. ICMS ECOLÓGICO: um Desafio à Sustentabilidade Econômico Ambiental no Amazonas. Revista Jurídica do Unicuritiba, vol. 02, n. 47, p. 251-276, 2017, p.256.

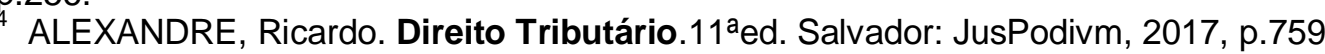


Personalidade Acadêmica Homenageada:

Florisbal de Souza Del'Olmo (Professor Convidado - UNICURITIBA)

O ISS possui forte caráter fiscal. Todavia, a Lei ํㅜ 157/2016, em que pese impor alíquota mínima de $2 \%$, admite a possibilidade de concessão de benefício fiscal abaixo de tal percentagem, senão vejamos:

Art. 8-A. A alíquota mínima do Imposto sobre Serviços de Qualquer Natureza é de $2 \%$ (dois por cento). $\S 11^{\circ} \mathrm{O}$ imposto não será objeto de concessão de isenções, incentivos ou benefícios tributários ou financeiros, inclusive de redução de base de cálculo ou de crédito presumido ou outorgado, ou sob qualquer outra forma que resulte, direta ou indiretamente, em carga tributária menor que a decorrente da aplicação da alíquota mínima estabelecida no caput, exceto para os serviços a que se referem os subitens 7.02, 7.05 e 16.01 da lista anexa a esta Lei Complementar (g.n)

Quanto às exceções destacadas no artigo acima, são as seguintes:

7 - Serviços relativos a engenharia, arquitetura, geologia, urbanismo, construção civil, manutenção, limpeza, meio ambiente, saneamento e congêneres. 7.02 - Execução, por administração, empreitada ou subempreitada, de obras de construção civil, hidráulica ou elétrica e de outras obras semelhantes, inclusive sondagem, perfuração de poços, escavação, drenagem e irrigação, terraplanagem, pavimentação, concretagem e a instalação e montagem de produtos, peças e equipamentos (exceto o fornecimento de mercadorias produzidas pelo prestador de serviços fora do local da prestação dos serviços, que fica sujeito ao ICMS).(g.n) 7.05 - Reparação, conservação e reforma de edifícios, estradas, pontes, portos e congêneres (exceto o fornecimento de mercadorias produzidas pelo prestador dos serviços, fora do local da prestação dos serviços, que fica sujeito ao ICMS).(g.n).

Portanto, verifica-se a possibilidade de instituição do ISS voltado à extrafiscalidade, principalmente no que tange a incentivar a construção civil a pautar sua atividade em consonância com os ditames de proteção ambiental.

Por outro lado, a mesma lógica pode ser lançada em relação ao IPTU (Imposto Territorial Urbano), o qual, de acordo com o art. 156, I, CF/88, também é de competência dos municípios.

Outrossim, segundo Sabbag ${ }^{5}$, "é fato que o poder de isentar, sendo correlato ao poder de instituir o tributo, implica que o IPTU só poderá ser isento por

\footnotetext{
${ }^{5}$ SABBAG, Eduardo. Manual de Direito Tributário. São Paulo: Saraiva, 2014, p. 1019.
} 
Personalidade Acadêmica Homenageada:

Florisbal de Souza Del'Olmo (Professor Convidado - UNICURITIBA)

uma lei ordinária editada pelo município competente". E, a respeito da extrafiscalidade do IPTU, Lima ${ }^{6}$ esclarece que:

O Imposto Predial e Territorial Urbano, por atingir grande parte dos poluidores das cidades, tem função primordial por meio de sua extrafiscalidade no desenvolvimento socioambiental, promovendo uma mudança de comportamento em todas as camadas socioeconômicas da população, bem como nas próprias pessoas jurídicas.

A título de exemplo, o Município de Itatiba, interior de São Paulo, instituiu o Programa Imposto Ecológico, por meio da Lei no 4.417/11, no qual se normatiza o benefício tributário relativo à redução do IPTU e ISS às pessoas físicas e jurídicas que adotem, dentre várias medidas sustentáveis, a construções com material sustentável:

\begin{abstract}
Art. 2ํ. Será concedido benefício tributário, consistente na redução do Imposto Predial e Territorial Urbano - IPTU e ISS - Imposto sobre Serviços de Qualquer Natureza, às pessoas físicas e jurídicas proprietárias de imóveis residenciais e comerciais que adotem medidas que estimulem a proteção, preservação e recuperação do meio ambiente. I - Para a obtenção dos benefícios previstos no IMPOSTO ECOLÓGICO, no caso do IPTU, deverão ser adotadas as seguintes medidas: a) Sistema de captação da água da chuva; b) Sistema de reuso de água; c) Sistema de aquecimento hidráulico solar; d) Sistema de aquecimento elétrico solar; e) Construções com material sustentável.(g.n)
\end{abstract}

Assim, a extrafiscalidade dos impostos relativos ao IPTU e ISS pode ser lançada à medida em que concilia a lucratividade esperada pelo empresário da construção civil e a preservação do meio ambiente, equacionando "lucro com ética e sustentabilidade".

\footnotetext{
${ }^{6}$ LIMA, André Lima de. IMPOSTO PREDIAL E TERRITORIAL URBANO (IPTU): A EXTRAFISCALIDADE COMO MECANISMO DE DESENVOLVIMENTO DO MEIO AMBIENTE ECOLOGICAMENTE EQUILIBRADO NA CIDADE DE MANAUS. 2015. Disponível em: < https://www.conpedi.org.br/publicacoes/c178h0tg/gb7cf8t2/ppQxB2Db0PDyV55G.pdf>. Acesso em: 22 de maio de 2018, p.374.
} 
Personalidade Acadêmica Homenageada:

Florisbal de Souza Del'Olmo (Professor Convidado - UNICURITIBA)

\section{RESULTADOS OBTIDOS OU ESPERADOS}

Os objetivos da pesquisa foram cumpridos, uma vez que se analisou a legislação pertinente e verificou-se que o ISS (Imposto sobre serviço de qualquer natureza) e o IPTU (Imposto Territorial Urbano) podem ser objetos de tributação extrafiscal, por parte da municipalidade, no intuito de estimular nas construtoras posturas positivas que salvaguardem o meio ambiente em face à utilização da matéria-prima na construção.

O ISS, em que pese seu caráter fiscal, também possui caráter extrafiscal, principalmente nas atividades elencadas nos subitens 7.02, 7.05 e 16.01 da lista anexa à Lei Complementar oㅜ116/2003, com enfoque especial às atividades típicas da construção civil.

De igual natureza, o IPTU também é importante instrumento na política estatal voltada à oferta de incentivos tributários em prol do desenvolvimento sustentável, podendo haver a isenção do respectivo imposto quando haja obediência a medidas previstas em leis que visem, por exemplo, o uso de sistema de aquecimento elétrico solar e construções com material sustentável.

Neste sentido, cabe à iniciativa econômica explorar a atividade lucrativa, mas deve fazê-lo com ética, buscando estabelecer relações de sustentabilidade e preservação ambiental. Se assim agir, a atividade econômica ganha mercado, uma vez que uma grande parcela da população do planeta terra está preocupada com as questões ambientais e buscam consumir produtos menos agressivos e prejudiciais ao meio ambiente.

Assim, sugere-se que a classe empresarial da construção civil, em vista dos incentivos tributários que obterão, adote medidas sustentáveis em sua atividade, contribuindo, consequentemente, para a proteção ambiental.

\section{TÓPICOS CONCLUSIVOS}

Diante todo o exposto, conclui-se que a extrafiscalidade aplicada ao ISS e ao IPTU exorta comportamentos positivos por parte do empresariado da construção 
Personalidade Acadêmica Homenageada:

Florisbal de Souza Del'Olmo (Professor Convidado - UNICURITIBA)

civil, estimulando por parte destes comportamentos positivos, a exemplo do uso de matérias sustentáveis, gerando a almejada proteção ambiental.

Observa-se, do mesmo modo, que o Estado, por meio da extrafiscalidade dos respectivos impostos, promove a Educação Ambiental prevista constitucionalmente à medida que revela os benefícios oriundos da observância da proteção ambiental. E isso é enaltecido não apenas pelo cunho lucrativo oriundo das isenções ou diminuições das alíquotas, mais também pela promoção da sadia qualidade de vida a todos.

Uma nova perspectiva é criada no momento em que modifica a forma como se realiza a proteção ambiental. Deixa-se de lado o viés punitivo em no tocante a atos da iniciativa privada, calcado na aplicação de multas. Igualmente, o cunho meramente reparatório é ineficaz quanto ao abrigo do meio ambiente, vez que o retorno ao status quo ante do dano ambiental é de extrema dificuldade.

Dessa forma, tem-se um novo olhar concernente à proteção ambiental face à atividade empresarial, qual seja, a implementação da extrafiscalidade dos impostos ISS e IPTU, estimulando práticas sadias por parte da iniciativa privada em consonância com os dogmas de preservação, atingindo, finalmente, a sustentabilidade. 